
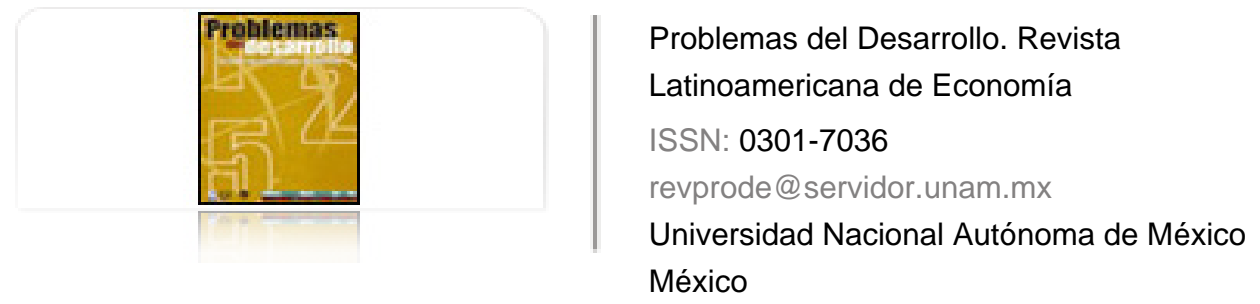

Alonso, José A.

Soberanía nacional y neoliberalismo en México: el nuevo sector manufacturero en Tlaxcala Problemas del Desarrollo. Revista Latinoamericana de Economía, vol. 37, núm. 145, abril-junio, 2006, pp. 81-103

Universidad Nacional Autónoma de México

Distrito Federal, México

Disponible en: http://www.redalyc.org/articulo.oa?id=11820086005

Cómo citar el artículo

- Número completo

- Más información del artículo

Página de la revista en redalyc.org

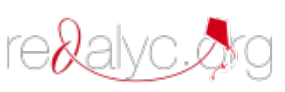

Sistema de Información Científica

Red de Revistas Científicas de América Latina, el Caribe, España y Portugal Proyecto académico sin fines de lucro, desarrollado bajo la iniciativa de acceso abierto 


\section{Soberanía nacional y neoliberalismo en MéXICO: EL NUEVO SECTOR MANUFACTURERO EN TLAXCALA}

\section{José A. Alonso*}

Fecha de recepción: 10 de octubre de 2005. Fecha de aceptación: 30 de marzo de 2006.

\section{Resumen}

Los países líderes en la actual economía-mundo capitalista destacan tanto por el vigoroso desarrollo de sus respectivos sectores manufactureros, como por la defensa a ultranza de su soberanía nacional. En ese contexto surge la pregunta acerca del impacto que ha ejercido la globalización neoliberal en el desarrollo de la industria nacional mexicana y, por ende, en el fortalecimiento de su soberanía. El análisis de la evolución del sector manufacturero en Tlaxcala permite observar que las grandes beneficiadas han sido las empresas foráneas porque en tan diminuto estado tiene lugar la lucha por la competencia mundial entablada entre la Unión Europea y Estados Unidos. Ni la autonomía regional ni la soberanía mexicana parecen beneficiarse hasta el momento de dicha política neoliberal.

Palabras clave: apertura, proteccionismo, soberania, maquila, regiones.

\section{Abstract}

The leader countries in the present capitalist world economy emphasize the vigorous development of their respective manufacturing sectors and the defense to the death of their national sovereignty. In this context, the question arises about the impact exercised by neoliberal globalization in the development of Mexico's national industry and, therefore, in the strengthening of its sovereignty. The analysis of the manufacturing sector's evolution in the state of Tlaxcala makes it possible to see that the great beneficiaries have been the foreign companies because such a tiny state is the setting for world competition starting up between the European Union and the United States. Neither regional autonomy nor Mexican sovereignty appear to be benefiting up to now from that neoliberal policy.

Key words: opening, protectionism, sovereignty, maquiladora, regions.

* Profesor e investigador en el Departamento de Relaciones Internacionales de la Universidad de las Américas, Puebla; pertenece al Sistema Nacional de Investigadores desde 1985, nivel II. El autor agradece el apoyo prestado por María Guadalupe Torres Nava de El Colegio de Tlaxcala, A.C. para la elaboración del presente artículo. Correo electrónico: caviedes01@hotmail.com 


\section{Résumé}

Les pays leader dans l'actuelle économie-monde capitaliste sont mis en relief aussi bien par le vigoureux développement de leurs respectifs secteurs de manufacture que par la défense à outrance de leur souveraineté nationale. Dans ce contexte la question sur l'impact exercé par la globalisation néolibérale dans le développement de l'industrie nationale mexicaine et, par conséquent, dans le renforcement de leur souveraineté surgit. L'analyse de l'évolution du secteur de manufacture dans l'état de Tlaxcala, nous permet d'observer que les grandes bénéficiaires ont été les entreprises étrangères puisque dans un aussi petit état a lieu la lutte pour la concurrence mondiale mise en place entre l'Union Européenne et les Etats-Unis d'Amérique. Ni l'autonomie régionale, ni la souveraineté mexicaine semblent bénéficier pour le moment de cette politique néolibérale.

Mots-cléfs: ouverture, protectionnisme, souveraineté, sous-traitance, régions.

\section{Resumo}

Os paises líderes na atualidade economia-mundo capitalista sobresaem tanto pelo vigoroso desenvolvimento dos seus respetivos setores manufatureiros, quanto pela férrea defesa da sua soberania nacional. Neste contexto nasce uma questão sobre o impacto que exerceu a globalização neoliberal no desenvolvimento da indústria nacional mexicana e por conseqüência, no fortaleciento da sua soberania. $O$ análise da evolução do setor manufatureiro do estado de Tlaxcala permite observar que as grandes beneficiadas foram as empresas estrangéiras pois num estado tão pequeño há uma luta pela competência mundial entre a União Europeia e os Estados Unidos. Nem a autonomia regional, nem a soberania mexicana parecem se beneficiar até agora desta política neoliberal.

Palavras chave: abertura, protecionismo, soberania, maquia, regiões.

\section{Desarrollo}


Hace mucho tiempo tengo la más firme convicción de que todo lo que México no haga por sí mismo para ser libre, no debe esperar ni conviene que espere que otros gobiernos u otras naciones hagan por él.

Benito Juárez*

\section{Introducción}

$\mathrm{L}$

os países capitalistas que destacan actualmente en el contexto internacional, conocidos como el G-7, poseen una vigorosa industria manufacturera. Todas esas

naciones tienen un perfil industrial específico, pero cada una se distingue por su sólida estructura manufacturera. En una primera aproximación estadística hoy día "apenas una veintena de países pueden ser considerados industrializados a nivel mundial" (Martínez y Vidal, 1995:227). Entre éstos destacan varias naciones europeas, Estados Unidos y Canadá, en América, y Japón, junto con Corea del Sur y China, en el bloque asiático. No obstante, es importante subrayar que sólo tres son las auténticas potencias industriales del mundo: Estados Unidos, Japón y Alemania. La producción manufacturera de éstos en 1990 representaba más de la mitad de la producción mundial de manufacturas y del valor añadido en la misma (Ibidem:232).

No es una casualidad que las tres naciones arriba mencionadas se hayan constituido en los líderes indiscutibles de los tres bloques socioeconómicos presentes en el mundo. ${ }^{1}$ Dichos países, a pesar de las disparidades cronológicas, coinciden en que su proceso de desarrollo capitalista se ha asentado en un vigoroso Estado-nación. Para que surja una robusta industria manufacturera se requiere la presencia activa de un control político y económico sobre el territorio que ocupan. Desde la perspectiva política, los países altamente industrializados destacan por la defensa inalterable de su soberanía nacional, de ahí que sea imprescindible discutir la vigencia de este concepto.

\section{La soberanía nacional en la era neoliberal}

La soberanía es "el poder supremo e independiente que tiene el estado (sic)". ${ }^{2}$ Ningún otro poder está sobre el Estado nacional, el cual tampoco se subordina a ninguna otra autoridad interna o externa. Una consecuencia crucial de la soberanía es que, por poseer el poder

* Archivos Privados de D. B. Juárez y D. Pedro Santacilia, México, SEP 1928, tomo I, p. 82.

1 No incluimos a China en esta lista debido a las características atípicas que mostró en las tres últi mas décadas. Aunque el asombroso crecimiento de la industria china no es más que una confirmación de nuestro argumento que reconoce el apoyo imprescindible del Estado para el desarrollo industrial.

2 http:server2.southlink.com.ar

\section{DeSarrollo}


supremo, el Estado nacional no tolera interferencias extranjeras. Un aspecto fundamental para comprender el término es que "la autonomía del estado está condicionada, aunque no determinada en un sentido fuerte, por su independencia de la acumulación de capital sobre la que su control está lejos de ser completo" (Giddens, 2000:62). Se establece, por tanto, una relación compleja entre dos factores distintos como son la autonomía del Estado y la acumulación de capital. En este último proceso, básico en el sistema capitalista, las empresas manufactureras desempeñan un papel insustituible para lograr la modernización de un país, es decir, la separación de la vida moderna de las instituciones típicas del mundo tradicional.

La relación entre la soberanía estatal y la acumulación del capital ha sufrido una mutación crítica en la época neoliberal. Ciertos autores no dudan en afirmar que el Estado ya no es el único depositario de la soberanía nacional (Sassen, 1998:81). Se reconoce, por tanto, la pérdida de soberanía de los estados en sus respectivas economías. Admisión evidente en varios politólogos mexicanos que, al analizar la nueva fisonomía de la soberanía nacional, confiesan que "ahora ya la soberanía no es sólo cuestión de los estados, pues participan los nuevos actores económicos no estatales" (Rubio, 1992:25).

La consecuencia lógica es que dichos autores ya no hablan del Estado benefactor, sino del Estado neoliberal, una de cuyas funciones básicas es promover un cambio sustancial en la estructura productiva nacional. En otras palabras, el objetivo de esa política interna del Estado neoliberal es llevar a cabo la globalización de los procesos productivos. Ésta, sin embargo, no entraña un significado unívoco. Desde la perspectiva teórica de la CEPAL (Rodríguez, 1980) y de Wallerstein (1974, 1987), entre otros historiadores, la evolución del sistema capitalista ha generado la escisión entre su centro y su periferia. No es posible, por ende, dejar el análisis en el nivel de abstracción propio de dicho sistema en el ámbito mundial. Es necesario bajarlo al de la división entre centro y periferia porque en ambos grupos de países se observan leyes y comportamientos distintos. Esta diversidad socioeconómica se refleja en la interpretación de la soberanía nacional en tiempos neoliberales.

Por eso, se nos antoja como un reconocimiento importante, pero insuficiente, la opinión de Panitch (1994:13), que considera un error no apreciar en su verdadera dimensión el nuevo papel del Estado. Según dicho autor (Ibidem:17), hoy día ha surgido un nuevo Estado que realiza funciones tradicionales, pero ya no para el capital nacional, sino para el global. Idea retomada de Cox (1992:27), para el que el Estado actual ya no es sólo responsable ante el capital nacional, sino ante todo ante el internacional. Estos autores hablan de la internacionalización del Estado neoliberal, gracias a la cual éste se ha convertido en mediador y no más un diseñador soberano de las políticas industriales.

Esta distinción entre el Estado mediador y el diseñador es clave para entender la relación actual entre el estado capitalista y la estructura industrial de cada país. En nuestra opinión,

\section{DeSarrollo}


no obstante, se requieren ciertas precisiones teóricas para captar en todo su vigor la diferencia entre ambos. Para lograr una más adecuada comprensión de la doble función estatal habría que insistir en que el Estado diseñador es propio únicamente de los países capitalistas centrales. Ningún Estado periférico puede atribuirse esa función que es indispensable en cualquier proceso de industrialización; más aún hoy con los adelantos típicos de la tercera revolución industrial.

En el centro capitalista, las grandes empresas transnacionales (en adelante, ET) acaparan casi exclusivamente todos los procesos científicos y tecnológicos que se requieren para generar y diseñar nuevos productos industriales. Pero la colaboración del Estado es fundamental para que esas empresas puedan coordinar las diversas etapas que median entre el diseño teórico y técnico y la producción y venta de la mercancía en cuestión. Este complicado proceso exige la elaboración de leyes pertinentes, los permisos correspondientes para allegarse las materias primas y, sobre todo, las condiciones sociales adecuadas para que las empresas puedan contar con la fuerza de trabajo abundante y barata que sea requerida. Los países periféricos, por el contrario, no pueden contar con un Estado capaz de convertirse en un diseñador de todas las etapas antes enumeradas. El Estado periférico neoliberal se ha convertido en un auténtico mediador, tanto en el proceso de producción, como en el de la comercialización. En la periferia, el Estado genera las condiciones adecuadas (territoriales, laborales, fiscales, entre otras) para que las ET se instalen en su territorio y lleven a cabo los procesos de manufactura y realización de mercancías de acuerdo con sus propias estrategias.

Esta colaboración de los estados periféricos con el capital transnacional no presenta las mismas características en los nuevos países industrializados (New Industrialized Countries, NIC) asiáticos y en los países de América Latina. En Asia, la industrialización estuvo en manos de empresas nacionales promovidas por el Estado (Müller, 1998:680). En México, por el contrario, la estrategia impuesta por el Fondo Monetario Internacional y el Banco Mundial contó con la colaboración de las élites políticas y empresariales para crear condiciones ventajosas para las nuevas inversiones extranjeras directas (IED). Con la entrada en vigor del Tratado de Libre Comercio de Norte América (TLCAN) en 1994, la desindustrialización nacional se acentuó gracias a que los programas de reconversión se transformaron en programas de privatización y a que las empresas y el capital extranjero comenzaron a dominar el panorama industrial. Las desventajas para México, y en general para América Latina, aumentaron porque la débil conciencia de la soberanía nacional impulsó a los gobiernos de la región a esperar que las ET resolvieran los problemas de generación de empleos, de la transferencia de tecnología y de la balanza de pagos. Este exceso de optimismo no tiene en cuenta que "las afluencias de capitales extranjeros tienen que ser menores que las futuras salidas de capitales ligadas a las remesas que retornan desde las sucursales hacia las matrices del centro capitalista" (Ibidem:696). De hecho, según la Conferencia de

\section{DeSarrollo}


las Naciones Unidas para el Comercio y Desarrollo (UNCTAD), entre 1970 y 1980 salieron de la periferia 1.50 dólares por cada dólar invertido (Gueck, Heidel, Kleinert, 1992:356). La culminación de esta tendencia entreguista en México la preparó el TLCAN y se consolidará con el ALCA, cuando quede constituido definitivamente el derecho de las empresas extranjeras a establecerse en los países latinoamericanos con mejores condiciones que las que disfrutan las empresas locales. El objetivo del capital internacional es poder instaurarse en cualquier país de la periferia con más derechos que los que disfruta en su país de origen, por eso: "el ALCA incluirá disposiciones acerca de inversiones similares a las que contenía el Acuerdo Multilateral sobre Inversiones y el Capítulo 11 del TLCAN, sobre las bases de las cuales las empresas podrán enjuiciar directamente a los gobiernos por las ganancias que se pierdan debido a la promulgación de leyes diseñadas para proteger la salud, la seguridad, las condiciones laborales o las normas ambientales" (Barlow, s.f.: 5).

En este contexto, cobran especial vigencia dos conceptos contrapuestos que se relacionan de inmediato con la soberanía nacional. Nos referimos a los conceptos de apertura y proteccionismo. El economista coreano Ha-Joon Chang (2002) ha defendido recientemente la tesis de que el desarrollo de la industria manufacturera en el sistema capitalista -al menos en sus etapas iniciales - es imposible sin una alta dosis de proteccionismo estatal. El autor muestra estadísticamente que países como Inglaterra y Estados Unidos, supuestos defensores de la política abierta comercial, aplicaron en su momento un agresivo proteccionismo tarifario (Chang, 2002:59) ${ }^{3}$ (véase cuadro en Apéndice). Hoy puede hablarse de una nueva oleada de proteccionismo en el centro capitalista (Dicken, 1992:151). En la periferia, por el contrario, predomina desde hace décadas el convencimiento de que la apertura ilimitada de la economía nacional es hoy día un ingrediente imprescindible para lograr el desarrollo socioeconómico de cualquier país. Si partimos del supuesto de que México aún no logra salir del círculo de la periferia surgen, de inmediato, diversas preguntas tanto en el nivel nacional como en el ámbito más restringido del estado de Tlaxcala: ¿qué ha ocurrido con la tradicional industria manufacturera mexicana en esta era neoliberal?, ¿cuál es el nuevo perfil de la industria en México y, en particular, en la región tlaxcalteca?, ¿cuáles son los cambios principales que se han producido debido a la aceptación irrestricta del modelo neoliberal?, ¿cuál es la lógica que promueve estos cambios?, ¿quién es el principal beneficiario de esta estrategia industrializadora? y, finalmente, ¿qué ha ocurrido con la soberanía nacional?, ¿es necesario aceptar la pérdida de soberanía con tal de lograr nuevos índices de industrialización?

Nuestra hipótesis es que la apertura indiscriminada a la inversión extranjera directa y, en concreto, al ingreso de las empresas transnacionales, si bien ha producido varios beneficios a México y al estado de Tlaxcala, en particular, ha relegado ante todo a la

3 Es obvio que las medidas proteccionistas no se aplican de manera constante, sino que cada país las ha aplicado de acuerdo con sus necesidades coyunturales (Chang, 2002:37).

\section{DeSarrollo}


tradicional industria de la región a segundo término y, a veces, a la extinción. Por ende, el predominio de la manufactura transnacional se perfila como una amenaza a la soberanía nacional. La excesiva apertura a la inversión extranjera ha dañado la tan celebrada soberanía de la nación mexicana. Ahora es el momento adecuado para preguntarnos qué debemos hacer en tan delicada coyuntura.

\section{La dialéctica entre soberanía y proteccionismo en el marco de la globalización neoliberal en México}

La interacción entre estas dos variables — soberanía y proteccionismo- ha sufrido una profunda redefinición en México a partir de 1982. En este contexto, las preguntas formuladas más arriba no son meramente retóricas. Basta con comparar la evolución de México con la de Corea del Sur, por ejemplo, para que surjan de inmediato los interrogantes. Según Calva (2000:7), México tenía un producto interno bruto (PIB) de 334.7 dólares per capita hace cuarenta años, mientras que en Corea del Sur sólo era de 157.9 dólares. Cuatro décadas después, este último poseía un PIB de 10500 dólares y México sólo alcanzaba los 3680 dólares. Para comprender tan dispares resultados no es preciso más que tener en cuenta los modelos de desarrollo aplicados en ambos naciones. El economista coreano John Lie (1998) explica tan exitosa industrialización capitalista de su país gracias a cuatro factores: el apoyo de la fuerza de trabajo barata, la inflexible reforma agraria, el fortalecimiento de un estado desarrollista y la ayuda de un entorno internacional favorable. Por el momento dejaremos de lado los dos primeros factores para concentrarnos en el gobierno coreano y en las inevitables relaciones internacionales. En ambos aspectos, como veremos, México sale mal parado de la comparación.

Presupuesta la desaparición de la clase terrateniente, debido a la implacable reforma agraria y a medidas estrictas, (Ibidem:291), el gobierno coreano se encargó de lograr que las enormes fortunas amasadas por la burguesía tradicional en los años sesenta no se convirtieran en un capital monopólico y rentista. Corea contó en esa coyuntura con un gobierno desarrollista auténtico, es decir, un Estado orientado a fomentar la acumulación de capital, aunque fuera en detrimento del bienestar social de las mayorías y de los intereses de corto plazo de los poderosos grupos económicos. Los nuevos empresarios industriales gozaron del apoyo estatal. El gobierno coreano eliminó tanto a los capitalistas parasitarios tradicionales, como a los poderosos burócratas corruptos. En definitiva, el Estado coreano disciplinó a la clase capitalista y sometió a la naciente clase trabajadora (Ibidem:293).

El otro factor indispensable en el caso coreano es la favorable coyuntura internacional. Debido a la amenaza de la China comunista y al creciente desafío industrial japonés, Estados Unidos apoyó de una manera decisiva el desarrollo capitalista de Corea del Sur para cimentar el triunfo militar obtenido en 1953 contra Corea del Norte. 
El panorama cambia radicalmente en el caso de México. La política industrial durante el sexenio de Miguel de la Madrid (1982-1988), diseñada por el equipo de Carlos Salinas de Gortari, se basó en la ideología sintetizada en export-led industrialization fueled by foreign investment and technology (ELIFFIT), un modelo de industrialización orientado a la exportación y alimentado por la inversión y la tecnología extranjeras (Sklair, 1988:11). A partir del comienzo de los años ochenta, México abandonó el modelo industrialización por sustitución de importaciones (ISI) para adoptar el de industrialización por sustitución de exportaciones (ISE), el cual respondía a los intereses del centro capitalista y, en particular, de las empresas transnacionales.

En efecto, pocos años antes el modelo liberal-conservador había sido instaurado en Japón y posteriormente en Gran Bretaña y Estados Unidos (Fröbel, 1983:118). Los rasgos básicos de dicho modelo son bien conocidos en el continente americano porque fueron retomados años más tarde por el Consenso de Washington. Destacan en éste los recortes salariales, el desmantelamiento del Estado benefactor, el debilitamiento de los sindicatos y las estrategias orientadas "al desvío de los recursos del Estado hacia medidas que sean rentables para la valorización del capital y para lograr un cambio en la reproducción de la fuerza de trabajo" (Ibidem:118).

Es importante subrayar el efecto positivo que estas medidas producían para fortalecer la soberanía nacional de los países centrales. La razón es que el conjunto de aquellas medidas serviría para aumentar la competitividad internacional de dichas naciones y, en concreto, de sus empresas transnacionales. Este modelo neoliberal, sin embargo, no tendría los mismos resultados benéficos en la periferia. Una razón, entre otras, es que la estrategia neoliberal de los países centrales contenía medidas concretas para favorecer el outsourcing (maquila internacional); en otras palabras, el traslado hacia la periferia de los procesos intensivos en fuerza de trabajo de sus empresas trasnacionales.

El crecimiento inusitado de las inversiones manufactureras extranjeras y de la maquila internacional durante las dos últimas décadas hubiera sido inconcebible sin la activa colaboración legal y jurídica de los respectivos gobiernos. Gilpin (2000:234) describe minuciosamente los pasos proteccionistas dados en Estados Unidos para contrarrestar el imparable poderío industrial japonés, el cual se veía agravado por la preocupante desindustrialización de la economía yanqui (Bluestone y Harrison, 1982).

Manifestaciones sucesivas del proteccionismo de Estados Unidos fueron, en primer lugar, la aplicación forzosa a Japón de las restricciones voluntarias a la exportación (VER). ${ }^{4}$ Además, el gobierno estadounidense autorizó en 1988 la famosa Super 301, que ordenaba a los representantes comerciales de Estados Unidos publicar la lista completa de los socios desleales (unfair) para aplicarles acciones antidumping e imponerles obligaciones compensatorias (countervailing duties) (Bhagwati, 1988:4, passim).

$4 \quad$ Las cursivas son nuestras.

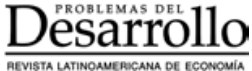


México ha sufrido desde 1994 los resultados de esa política proteccionista estadounidense, concentrada en el TLCAN. Este tratado no es más que otra manifestación del abandono por parte de Estados Unidos del multilateralismo, para caer en el más innegable unilateralismo. Es bien conocido el interés complaciente con el que participaron las autoridades mexicanas en turno para firmar y justificar el tratado (Von Bertrab, 1996). Dicho interés ha sido avalado por investigadores privados que no dudaron en afirmar que "el TLCAN es un instrumento que se ha convertido en la pieza central para la nueva estrategia de desarrollo" (Rubio, 1992:31).

Luis Rubio aludía a la necesidad de firmar el TLCAN para sustituir el proceso de integración silenciosa de la economía mexicana por una integración negociada entre ambos países (Villarreal, 1992:661). ${ }^{5}$ Tal colaboración entre ambos gobiernos no llegó a su fin con el TLCAN. Al contrario, actualmente se dan pasos inciertos para promover la plena aceptación del ELIFFIT mediante el Plan Puebla-Panamá y el ALCA. ${ }^{6}$

\section{Manifestaciones regionales de la politica neoliberal en México}

Las repercusiones de la estrategia adoptada por las élites mexicanas para promover el desarrollo de la industria nacional no han penetrado por igual en todas las regiones del país. En el caso concreto de la expansión maquiladora, fruto legítimo del ELIFFIT, abundan las investigaciones relacionadas con el crecimiento de la inversión extranjera, en general, en la zona norte del territorio nacional. En el centro, un buen grupo de investigadores hemos constatado la expansión de la maquila desde hace treinta años en un movimiento que arrancó desde la frontera mexicano-estadounidense y que hoy ha llegado a casi todas las provincias de la república mexicana. A pesar de su diminuto tamaño, el estado de Tlaxcala posee unas características propias que le convierten en atractivo objeto de estudio.

5 Cita de Villarreal en Claudia Avila Connely, "El mercado de América del Norte, espacio económico para México", en Comercio Exterior, núm. 41, México, julio de 1992, p. 661.

6 La literatura relacionada con el impacto del TLCAN es abundante. José Luis Calva (El Universal, 11 de noviembre de 2005) acaba de presentar algunos datos irrefutables para desvanecer los espejismos que dicho tratado provocó en su momento. Bastará con mencionar ciertos indicadores: durante el periodo neoliberal (1983 2004) el PIB per capita creció a una tasa media de $0.6 \%$ anual, mientras que durante el lapso precedente (1935 1982) creció a una tasa media anual de 3.2\%. Durante este periodo los salarios se incrementaron $96.9 \%$, mientras que en la época neoliberal perdieron $69.8 \%$. En el tema que nos concierne, las manufacturas, Calva proporciona datos sugerentes: en la época del TLCAN las exportaciones manufactureras, sin incluir las maquiladoras, crecieron a precios constantes a una tasa media de 9.5\% anual, mientras que durante 1951 1981 habían crecido a $11.5 \%$ anual. Añadamos, para concluir, que tampoco en la creación de empleos - como se nos había prometido - la estrategia neoliberal tuvo el éxito esperado. Durante el lapso 1998 2004, los demógrafos estiman que alrededor de 2 millones 750 mil mexicanos emigraron a Estados Unidos. La razón es que, en vez de crecer la economía a una tasa anual de 6\% para generar suficientes empleos, en el periodo del TLCAN, la tasa de crecimiento ha sido de $2.5 \%$. 
De cualquier manera, es necesario situar el desarrollo industrial reciente del estado de Tlaxcala en el punto de convergencia entre los intereses subcontratistas de las ET y las políticas regionales generadas a partir de 1982 por el Estado mexicano. El fenómeno de las desigualdades regionales ha sido analizado en México desde los años setenta (Unikel, 1976). El Estado mexicano respondió a la creciente disparidad regional mediante la creación de dos estrategias de desarrollo regional: la descentralización industrial —vía parques industriales - y la inauguración de programas regionales de empleo (Carrillo, 2002:75). Ambas estrategias inciden obviamente en el estado de Tlaxcala, aunque desde el punto de vista del desarrollo integral de la industria constataremos que el impacto de los planes oficiales es muy limitado por el favor prestado al modelo de la subcontratación internacional, en el que las empresas se nutren de insumos y de personal gerencial proveniente de otras naciones.

Carrillo (2002:83) reconoce que el periodo 1970-1982 marca el momento en el cual los gobiernos mexicanos se apoyaron más en la planeación para fomentar un desarrollo regional más equitativo. En ambos sexenios la preocupación por las disparidades regionales se incorporó a la agenda del desarrollo en México. Sin embargo, insiste Carrillo, en las dos décadas siguientes se abandonó la planeación como método de promoción del desarrollo. En síntesis, la planeación regional no ha sido considerada como guía de acción gubernamental para el desarrollo socioeconómico de México durante la fase neoliberal.

\section{Perfil actual de la industria manufacturera en Tlaxcala}

El desarrollo reciente de las manufacturas en Tlaxcala es una muestra diáfana de los nuevos criterios de planeación del Estado mexicano para lograr el crecimiento económico del país y asegurar, al mismo tiempo, la generación de empleos. A continuación presentamos un esbozo de las principales características que presenta en las últimas décadas la industria manufacturera localizada en el estado de Tlaxcala. Entre éstas destacan las siguientes: ${ }^{7}$

1) La presencia de una sólida infraestructura, promovida por las autoridades federales y estatales, sin la cual no habría podido darse el proceso de industrialización en las dos últimas décadas. El resultado visible de este esfuerzo mancomunado es la creación de tres parques industriales en los cuales se han instalado múltiples empresas nacionales y foráneas. La consecuencia obvia de esas políticas oficiales ha sido la alta tasa de crecimiento experimentada por el sector manufacturero entre 1970 y 2003.

2) El crecimiento de la manufactura ha producido un cambio radical en la estructura productiva del estado: Tlaxcala se ha convertido de estado agrícola a uno en el cual predominan los sectores industrial y de servicios.

$7 \quad$ Esta síntesis se apoya en sendos avances de investigación elaborados por Ma. de los Ángeles Nava Martínez y María Guadalupe Torres Nava, investigadoras de El Colegio de Tlaxcala, A.C.

\section{DeSarrollo}


3) La manufactura, sin embargo, no se ha repartido de manera uniforme por todo el estado. La industria se ha concentrado en la región centro-sur y, más en particular, en siete municipios de esa zona.

4) Un aspecto muy destacable es la diversificación industrial experimentada en el estado. Hoy día más municipios cuentan con más tipos de industrias.

5) En 2003 el estado de Tlaxcala contaba con 376 empresas manufactureras, entre las cuales destacan la rama de la confección con 97 empresas (25.8\%) y la textil, con 107 (28.4\%). Las ramas textil y de la confección representan $54.2 \%$ de la manufactura instalada en el estado de Tlaxcala. Siguen, a gran distancia, la metal-mecánica (6.6\%), la de minerales no metálicos $(5.6 \%)$ y la de plásticos (5\%). No obstante, una prueba del cambio productivo experimentado por el estado es la débil presencia de la industria de alimentos (3.7\%), muy próxima a la de los sectores automotriz (3.5\%) y químico $(3.2 \%)$.

6) Es necesario, sin embargo, matizar esta información teniendo en cuenta el tamaño de las empresas y el número de trabajadores empleados en cada rama de actividad. Así, en la textil $47.6 \%$ de las empresas son micro, $30.8 \%$ son pequeñas, $20.5 \%$ son medianas y sólo $1 \%$ es grande $(0.9 \%)$; mientras que en la rama de la confección $49.5 \%$ son micro, $24.7 \%$ son pequeñas, $21.6 \%$ son medianas y $4.2 \%$ son grandes. Ambas ramas, por una parte, son las mayores generadoras de empleo con 8633 trabajadores en el área textil y 14180 en la de la confección. Por el contrario, la rama automotriz, que sólo cuenta con 13 empresas en el estado, es la cuarta generadora de empleos con 4232 sólo por detrás de la rama de minerales no metálicos con 4 536. Sólo una empresa automotriz es micro, mientras que en la de minerales no metálicos son cuatro; aunque en ambos casos hay un predominio de empresas medianas y grandes: 10 en la automotriz y 9 en la de minerales no metálicos.

7) Información reciente de la Secretaría de Desarrollo Económico (sEDECO, 2003) nos permite precisar con más rigor las características de las ocho principales ramas manufactureras atendiendo al número de las empresas. Las ramas son las siguientes: textil (107 empresas), confección (97), metalmecánica (25), minerales no metálicos (21), plásticos (19), alimentos (14), automotriz (13) y química (12). Las ocho muestran notables diferencias en cuanto al tamaño de las empresas, tal como se muestra en el Cuadro 1.

Destaquemos, en primer lugar, que las ocho ramas seleccionadas son las que cuentan con el mayor número de empresas y las que generan mayor número de empleos. Llama la atención, sin embargo, la estructura polarizada que se observa en dichas ramas. Todavía en 2003 sobresalen las ramas textil y de la confección en ambos rubros, es decir, el número de empresas y el número de empleos generados.

\section{DeSarrollo}


Cuadro 1

Empresas manufactureras del estado de Tlaxcala, por rama de actividad y tamaño, 2003

\begin{tabular}{lccccc}
\hline \multicolumn{1}{c}{$\begin{array}{c}\text { Ramas } \\
\text { de actividad }\end{array}$} & Micro & $\begin{array}{c}a \\
\text { Pequeña }\end{array}$ & $\begin{array}{c}a \\
\text { Mediana }\end{array}$ & $\begin{array}{l}\text { o } \\
\text { Grande }\end{array}$ & $\begin{array}{c}\text { Núm. } \\
\text { de empresas }\end{array}$ \\
\hline Textil & $51(47.6 \%)$ & $33(30.8 \%)$ & $22(20.5 \%)$ & $1(0.9 \%)$ & 107 \\
Confección & $48(49.5 \%)$ & $24(24.7 \%)$ & $21(21.6 \%)$ & $4(4.2 \%)$ & 97 \\
Metal mecánica & $16(64 \%)$ & $6(24 \%)$ & $2(8 \%)$ & $1(4 \%)$ & 25 \\
Minerales no metálicos & $8(38 \%)$ & $4(19 \%)$ & $6(28.6 \%)$ & $3(14.3 \%)$ & 21 \\
Plásticos & $7(36.8 \%)$ & $4(21 \%)$ & $7(36.8 \%)$ & $1(4.8 \%)$ & 19 \\
Alimentos & $4(28.6 \%)$ & $4(28.6 \%)$ & $5(35.6 \%)$ & $1(7.2 \%)$ & 14 \\
Automotriz & $1(7.8 \%)$ & $2(15.4 \%)$ & $6(46.1 \%)$ & $4(30.7 \%)$ & 13 \\
Química & $6(50 \%)$ & $5(41.6 \%)$ & $1(8.4 \%)$ & 0 & 12 \\
Petroquímica & $6(30 \%)$ & $7(35 \%)$ & $7(35 \%)$ & 0 & 20 \\
\hline
\end{tabular}

Fuente: SEDECO (2003), Directorio de empresas del estado de Tlaxcala, por rama de actividad, Gobierno del estado de Tlaxcala, Tlaxcala.

Los esfuerzos por industrializar y modernizar la planta productiva del estado de Tlaxcala han propiciado la aparición de industrias tan representativas de la nueva tecnología como la automotriz y la química. Pero las industrias textil y de la confección todavía ocupan los dos primeros lugares en el perfil manufacturero del estado en cuanto a los dos rubros arriba mencionados.

Otro factor que muestra el carácter sesgado de la industrialización en esta provincia es la clara hegemonía de las microindustrias en casi todas las ramas seleccionadas. En todas ellas, el grupo de grandes empresas es minoritario, con la débil excepción de la rama automotriz, en la cual prevalecen las empresas medianas (46.1\%) y las grandes (30.7\%). Las microindustrias predominan en las tres primeras ramas industriales del estado y en una tan moderna como la química (50\%). La abundancia de microindustrias en una rama tan representativa de Tlaxcala como es la confección adquiere matices especiales gracias a la presencia de la informalidad en casi todos los niveles de la industria manufacturera estatal (Alonso, 1997).

Las políticas estatales de modernización deberán presentar cuidadosa atención a esta estructura polarizada de la reciente industrialización porque las microempresas actuales no son sólo remanentes del pasado. La estrategia neoliberal imperante fomenta el surgimiento y la refuncionalización de las micro y pequeñas industrias en casi todas las ramas industriales (Ibidem, 1997).

8) En el contexto de la modernización debe subrayarse, por su impacto frontal en el sector manufacturero, la apertura económica promovida por la globalización neoliberal. Dicha apertura se manifiesta en un doble frente: el fomento de la inversión extranjera y el crecimiento de las empresas maquiladoras.

\section{DeSarrollo}


El gobierno mexicano ha operado la apertura al capital extranjero mediante diversos programas:

- Empresas exportadoras.

- Empresas altamente exportadoras (AlTEX). En 1996, la SECOFI (hoy Secretaría de Economía, SE) las definía como empresas exportadoras directas que demuestran saldo favorable en su balanza comercial y exportaciones directas por un valor mínimo anual de 3 millones de dólares, cantidad que debe representar al menos $40 \%$ de sus ventas totales.

- Empresas en programa de importación temporal (PITEX) para producir artículos de exportación. Desde 1996, la SE autorizó el programa PITEX a los exportadores que realicen ventas al exterior por un valor superior a 500000 usD, o bien, facturen productos de exportación de cuando menos $10 \%$ de sus ventas totales.

- Empresa maquiladoras de exportación.

- Empresas con inversión extranjera.

Veamos cada uno de estos rubros por separado.

a) Empresas ALteX. En 1991, la SE indicaba la existencia de doce, una de las cuales pertenecía a la rama 3220, es decir, a la industria de la confección. Otras siete empresas provenían de la rama química.

A fines de 1994 el total de este tipo de empresas en la entidad ascendía a 14, de las cuales cinco pertenecían a la rama de la confección, situadas en los municipios de Contla (3), de Chiautempan (1) y de Tlaxcala (1). En 1996, la SE registraba ya la existencia de 17; mientras que para 2003 eran 13.

b) Empresas PITEX. En 1991, la SE declaraba la existencia de nueve, de las cuales sólo una pertenecía a la rama 3220. Pero dicha firma había desaparecido para 1994, aunque el total de ese tipo de empresas en la entidad ascendía ya a 19 en total.

El gran cambio se detecta en 1996, año en el cual se contabilizan 39; mientras que en 2003 eran 58.

c) Empresas maquiladoras de exportación. Se ubican en este apartado las empresas pertenecientes a personas físicas de nacionalidad mexicana o a las personas morales debidamente constituidas en términos de la legislación nacional (SE, 1989), que exportan la totalidad de su producción.

En 1994 se identificaban siete de tales empresas en el estado de Tlaxcala, seis de las cuales pertenecían a la rama de prendas de vestir. Tres de estas seis maquiladoras se encontraban en el municipio de Tlaxco y las otras tres en Chiautempan, Tetla y Nanacamilpa. A finales de 1996, el número de tales empresas se había elevado a 18, de

\section{DeSarrob}


Cuadro 2

Empresas del estado de Tlaxcala con inversión extranjera, por rama de actividad y país de origen, 2003

\begin{tabular}{|c|c|c|c|c|c|c|c|c|c|c|}
\hline Ramas de actividad & Alemania & Canadá & Corea & España & E.U. & Francia & Suecia & Suiza & Italia & Bélgica \\
\hline Textil & 1 & & 1 & & 2 & & & & & \\
\hline Automotriz & 6 & & & & 2 & & & & & \\
\hline Plástico & 1 & & & & & 1 & & & & \\
\hline Madera & 1 & & & & & & & & & \\
\hline Química & 1 & & & & 4 & & 1 & & & \\
\hline Calzado & & 1 & & & & & & & & \\
\hline Confección & & & & & 8 & & & & & \\
\hline Metálica básica & & & & 1 & & 1 & & & & 1 \\
\hline Minerales no metálicos & & & & 1 & 1 & & & & & \\
\hline Metalmecánica & & & & & 1 & & & & & \\
\hline Productos eléctricos & & & & 1 & & 1 & & & & \\
\hline Agroindustria & & & & & 2 & & & & & \\
\hline Electrónica & & & & & 1 & & & & 1 & \\
\hline Papel & & & & & 2 & & & & & \\
\hline Petroquímica & & & & & 1 & & 1 & & & \\
\hline Alimentos & & & & & & & & 1 & & \\
\hline
\end{tabular}

Fuente: elaboración propia con base en SEDECo (2003), Directorio de empresas del estado de Tlaxcala, por rama de actividad y tipo de inversión extranjera, Gobierno del estado de Tlaxcala, Tlaxcala.

las cuales 14 eran de la rama de la confección. En 2003 estas empresas ascienden a ocho.

d) Empresas con inversión extranjera. En 1995 se hallaban 29, de ellas sólo cuatro pertenecían a la rama de prendas de vestir. En Tetla se ubicaban dos, otra en Chiautempan y otra en el municipio de Tlaxcala.

A partir de la entrada en vigor del TLCAN (1994) se ha incrementado de manera consistente, aunque irregular, la inversión extranjera en el estado de Tlaxcala. Según SEDECO, en los últimos cuatro años (1999-2002) la inversión extranjera total ascendió a 375.34 millones de dólares, pero el monto ha disminuido desde 184.50 millones en 1999 a un mínimo de 19.85 en 2002.

El Cuadro 2, elaborado con información de la SEDECO y de la SE, nos muestra la existencia de 47 empresas con inversión extranjera en el estado de Tlaxcala en agosto de 2003. El desglose por países y por ramas de actividad proporciona pistas certeras para detectar el papel que desempeña el desarrollo manufacturero en el contexto de la globalización actual. Destacan, en primer lugar, las industrias automotriz y de la confección, seguidas por la textil y la química. Aunque es importante subrayar que la inversión extranjera se encuentra muy diversificada, pues se halla presente en dieciséis ramas industriales.

\section{Desarrollo}




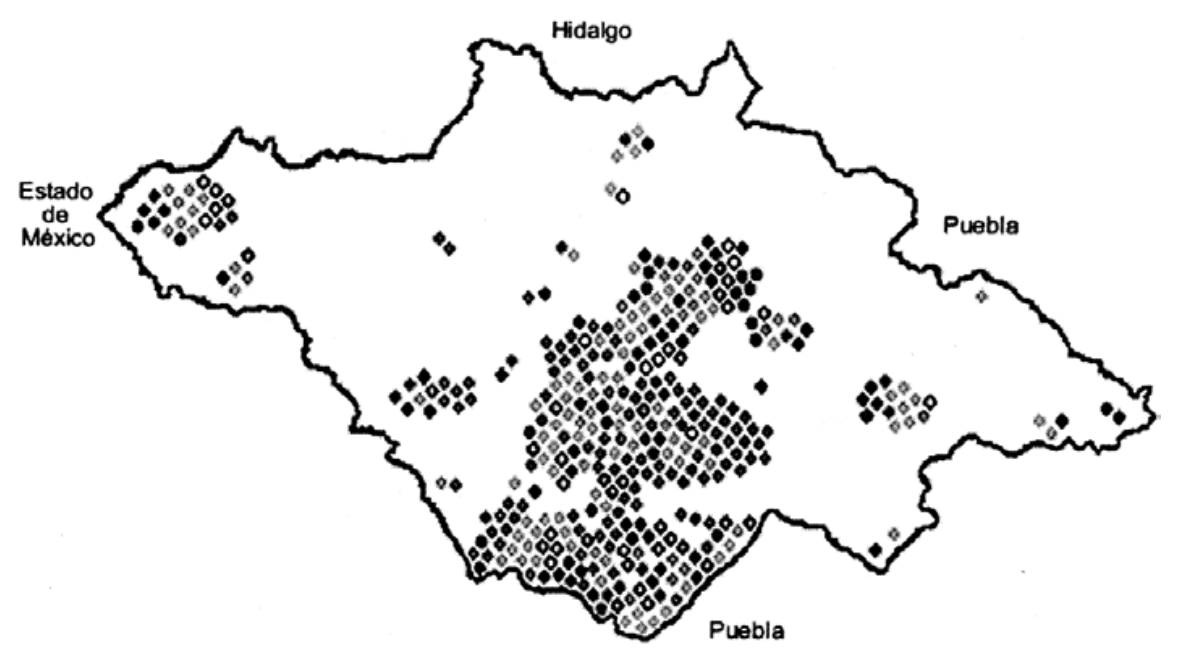

Mapa 1. Empresas manufactureras pequeñas, medianas y grandes del estado de Tlaxcala, 2003.

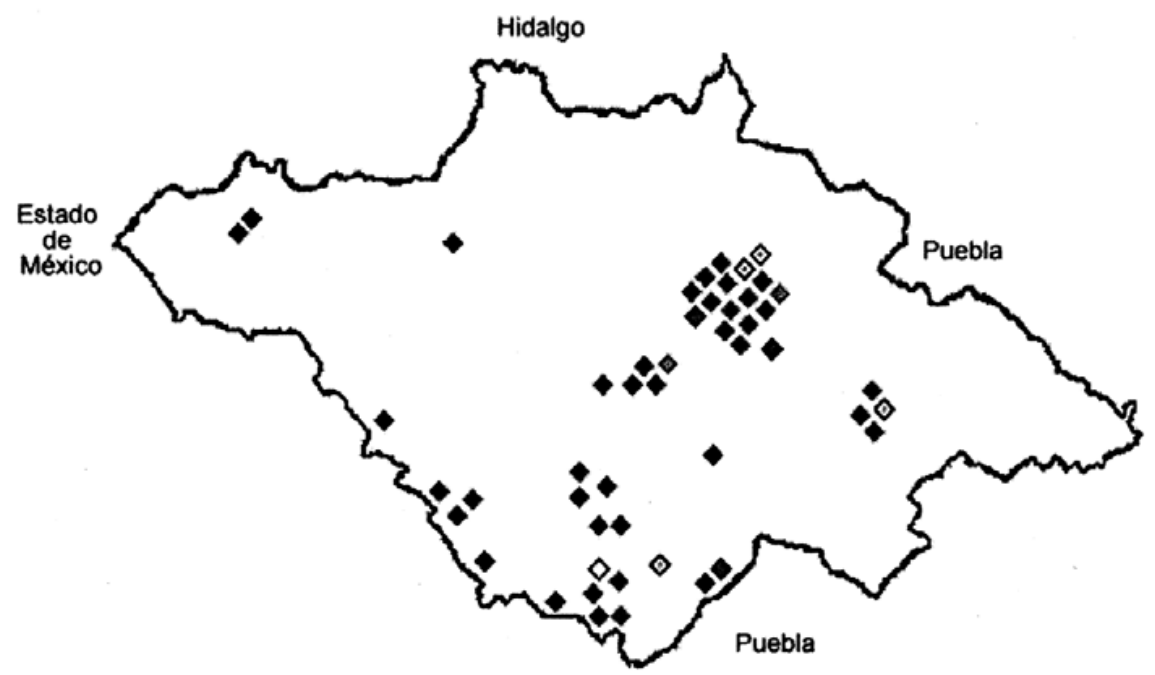

Mapa 2. Localización de empresas manufactureras con inversión extranjera del estado de Tlaxcala, 2003.

Como se ha señalado, esta diversidad productiva no se ve correspondida por la distribución geográfica, pues la mayoría de las empresas se concentran en la zona centrosur del estado de Tlaxcala. Las empresas que se localizan en otros municipios se ven atraídas por la cercanía al Distrito Federal, en el caso de Calpulalpan, o por el parque industrial de Tetla, en el caso de los municipios norteños.

La clasificación del país de origen es un diáfano indicador de los intereses nacionales en el actual mundo globalizado. Así, más de la mitad de las empresas con inversión extranjera proceden de Estados Unidos (24) y aunque se hallan distribuidas en once ramas distintas, 
Cuadro 3

Empresas de la rama de la confección exportadoras y no exportadoras del estado de Tlaxcala, por tamaño, 1996

\begin{tabular}{|c|c|c|c|c|}
\hline Tamaño de empresa & \multicolumn{2}{|c|}{$\begin{array}{c}N o \\
\text { Abs. }\end{array}$} & \multicolumn{2}{|c|}{$\begin{array}{lllllll}E & x & p & o & r & t & a\end{array}$} \\
\hline Grande & & & 4 & 16.0 \\
\hline Mediana & 7 & 9.7 & 13 & 52.0 \\
\hline Pequeña & 20 & 27.8 & 4 & 16.0 \\
\hline Micro & 45 & 62.5 & 4 & 16.0 \\
\hline Total & 72 & 100.0 & 25 & 100.0 \\
\hline
\end{tabular}

Fuente: elaboración propia con base en SE (2003), Relación de empresas con programas de exportación, delegación Tlaxcala, Tlaxcala.

es importante notar que predominan las industrias de la confección (ocho), mientras que sólo se encuentra una firma electrónica con capital estadounidense. Es llamativo el contraste con el otro miembro del TLCAN, pues sólo hay una empresa con capital canadiense en el estado.

Siete naciones de la Unión Europea han invertido en Tlaxcala. La preeminencia de Alemania con diez empresas se explica por la cercanía de la Volkswagen, situada en los límites de Puebla con el estado de Tlaxcala. En efecto, seis de estas empresas fabrican diversos componentes para la firma germana. A diferencia de Estados Unidos, ningún país europeo se interesa por la rama de la confección. Las empresas del vestido europeas prefieren maquilar las prendas de vestir en Asia o en el norte de África.

Las otras diez empresas con capital europeo se encuentran muy diversificadas en las distintas ramas de actividad y también por país. En conjunto, las veinte empresas de capital europeo muestran el interés de la Unión Europea (UE) por incrementar su presencia en México, debido a la cercanía con el mercado estadounidense. Destaca, sin embargo, el predominio alemán con la Volkswagen. Por el contrario, el bloque asiático pasa casi desapercibido, pues sólo Corea tiene inversión en una firma textil.

\section{Análisis de la confección}

Dada la preeminencia tradicional y aún vigente de la industria de la confección en el estado de Tlaxcala, conviene concluir este análisis con una referencia especial a esta rama industrial.

El Cuadro 3 presenta las 97 empresas de la confección divididas en exportadoras y no exportadoras, de las cuales sólo 25 exportan directamente. Las empresas más exportadoras son las grandes y, sobre todo, las medianas; mientras sólo cuatro de las microempresas exportan. Más llamativos son los datos concentrados en el Cuadro 4, en el cual se pueden apreciar los elevados porcentajes de incremento experimentados entre 1996 y 2003 por

\section{DeSarrollo}


Cuadro 4

Empresas de la rama de la confección exportadoras en el estado de Tlaxcala, 1996 y 2003

\begin{tabular}{lccc}
\hline \multicolumn{1}{c}{ Tipo de empresa } & Mayo 1996 & Agosto 2003 & Incremento \% \\
\hline Empresas exportadoras & 21 & 128 & 653 \\
Empresas ALTEX & 7 & 13 & 85.7 \\
Empresas PITEX & 3 & 58 & 1833.3 \\
Maquila de exportación & 14 & 8 & -57 \\
Empresas con inversión extranjera & 4 & 46 & 1050 \\
\hline Total & 49 & 253 & \\
\hline
\end{tabular}

Fuente: elaboración propia con base en SE (2003), Relación de empresas con programas de exportación, delegación Tlaxcala, Tlaxcala.

todos los tipos de firmas exportadoras, con excepción de las maquilas de exportación las cuales disminuyeron $57 \%$.

Es imposible concluir la presentación del sector manufacturero actual en el estado de Tlaxcala sin hacer una referencia al sector informal, el cual, por definición, es clandestino. No existen, por tanto, cifras confiables al respecto, aunque el mismo gobierno reconoce que, en algunas ramas industriales, al menos la mitad de las empresas actúan en la informalidad. Tal es el caso de la industria de la confección.

Aunque empresas de la confección clandestinas pululan en todo el estado, éstas tienden a concentrarse alrededor de las zonas urbanas. En alguna región están organizadas, aunque carecen del poder indispensable para lograr precios justos por las prendas que ensamblan. Los micromaquiladores clandestinos se quejan de que los precios han bajado en los últimos años debido a la crisis. Así, conjuntos de dama que hace algunos años se pagaban a 80 y 90 pesos, ahora no pasan de 65. La excusa dada por los intermediarios es que ahora la industria mexicana del vestido debe competir con los chinos y, próximamente, con los países centroamericanos. Estos microempresarios se quejan de que empresas comerciales como Zara y Liverpool son trianguladoras, es decir, ellas compran ropa barata y después la reetiquetan. Otra queja constante es que el gobierno da preferencia al capital extranjero.

\section{Hacia una interpretación de los procesos analizados}

Una síntesis apretada de los datos empíricos expuestos en la sección precedente nos permitiría confirmar la hipótesis formulada previamente. Pero más que la simple constatación cuantitativa, se requiere penetrar en el concepto de soberanía que subyace en las tendencias observadas. En primer lugar, es manifiesta la convergencia entre las políticas industriales, adoptadas en el estado de Tlaxcala, y los intereses estratégicos de las ET. El estado tlaxcalteca se ha convertido en un excelente mediador entre las ET, ampliamente favorecidas por las políticas industriales adoptadas por el gobierno mexicano, y el sector manufacturero 
nacional, que ha recibido el impacto sin la debida preparación. El estado de Tlaxcala se ha convertido en un simple receptor de las ET, las cuales se han instalado en tan pequeño estado porque así conviene a sus intereses geoestratégicos. Son estas ET las que han elegido el programa más conveniente entre los múltiples ofrecidos por el gobierno de Tlaxcala.

En efecto, los programas más exitosos desde 1991 son el PITEX y el de las empresas con inversión extranjera. A diferencia del ALTEX, con empresas altamente exportadoras y cuyo número apenas varió en una unidad entre 1991 y 2003, las PITEX y las empresas con inversión extranjera han experimentado un crecimiento espectacular en el mismo intervalo. Las PITEX aumentaron de nueve en 1991 a 58 en 2003 y las de inversión extranjera pasaron de 29 en 1995 a 47 en 2003. Tendencias semejantes se observan en el Cuadro 4, en el cual se comparan los datos correspondientes a 1996 y 2003. Frente al crecimiento observable en las firmas con capital extranjero contrasta, como aparece en dicho cuadro, la disminución sufrida por las empresas maquiladoras de exportación que son "empresas pertenecientes a personas físicas de nacionalidad mexicana".

En segundo lugar, el gobierno mexicano, apoyado en el ELIFFIT y el TLCAN, se ha convertido en un excelente mediador a favor de las empresas foráneas y en detrimento de las nacionales. Las ET se sienten muy complacidas porque, gracias a la comprensión del gobierno mexicano, han podido llevar a cabo sus propias estrategias geopolíticas. El capital estadounidense se ha concentrado en el sector de la confección porque cada vez le resulta menos rentable mantener en su propio territorio las empresas muy intensivas en fuerza de trabajo. Además las firmas yanquis y las europeas ya no son simplemente exportadoras; es decir, no les interesa el programa ALTEX. Gracias a los otros dos programas ahora producen también para el mercado nacional. El resultado obvio es que las empresas de capital nacional, específicamente en el área de la confección, se ven desplazadas de los mercados internacional y nacional. La estrategia de las empresas productoras foráneas se ve, a su vez, complementada por las grandes empresas comercializadoras nacionales (Liverpool, El Palacio de Hierro) y extranjeras (Wal-mart) que reciben sus mercancías procedentes de fábricas maquiladoras instaladas en territorio mexicano.

\section{A manera de conclusión: la soberanía en México a la luz de la experiencia tlaxcalteca}

El perfil de la industria manufacturera en el estado de Tlaxcala, que acabamos de presentar, es el resultado lógico de la colaboración entre el capital extranjero y las élites políticas y empresariales tlaxcaltecas. Sin la sinergia eficaz de ambos actores habría sido impensable el avance rápido y vigoroso del sector industrial en esta provincia. Los principales beneficiarios en este proceso, desarrollado con el patrocinio del ELIFFIT, son las ET y los empresarios nacionales ligados al capital extranjero. En Tlaxcala las ET gozan de ventajas difíciles de encontrar en sus países de origen. Además de contar con mano de obra eficiente

\section{DeSarrollo}


y barata, estas empresas disfrutan de innegables ventajas geoestratégicas. Las empresas estadounidenses, dominantes en el estado, son claramente mayoritarias en las áreas productivas que requieren abundante mano de obra barata. Pero es superfluo añadir que los procesos de diseño y el control de la producción permanecen en las oficinas matrices localizadas en lugares tan distantes de Tlaxcala como Los Ángeles o Nueva York. Las firmas europeas, por su parte, consideran a esta provincia un ventajoso trampolín para exportar a Estados Unidos sin tener que cruzar de nuevo el océano Atlántico.

Esta relocalización de las ET genera otras consecuencias nada despreciables. Las élites empresariales, que coordinan el timón del proceso industrializador en Tlaxcala, ya no son mexicanas. Las industrias tradicionales tales como la textil y del vestido, de profunda raigambre en esta provincia desde la Colonia, giran ahora alrededor de intereses y planes estratégicos foráneos. Esto no significa que las empresas medianas y pequeñas nacionales desaparezcan. Pero, en palabras de una experimentada empresaria de Chiautempan, municipio tlaxcalteca altamente industrializado, antes estos empresarios eran productores y ahora son simples maquiladores. Es decir, han perdido el control del proceso de producción.

Esta pérdida de autonomía a nivel empresarial encaja, obviamente, con la pérdida de soberanía en el nivel nacional. De ahí que las crisis y fluctuaciones económicas de Estados Unidos repercutan inmediatamente en el corazón del territorio mexicano. Tales cambios estructurales de la industria tlaxcalteca exigen una interpretación teórica. ¿Qué significa este nuevo perfil industrial desde la perspectiva del Estado-nación mexicano? ¿No afecta a la soberanía nacional el hecho innegable de que las élites políticas y empresariales mexicanas pierdan el control de las manufacturas? ¿Hacia dónde nos llevará esta renuncia a la soberanía nacional?

Ciertos politólogos mexicanos proclaman la necesidad de reconceptuar la soberanía del Estado mexicano (Rubio, 1992:29). Para llevar a cabo este proceso, dichos autores critican la teoría de la dependencia por haber sido la inspiradora de políticas nacionalistas que, a su vez, generaron el tan criticado nacionalismo mexicano. Pero, uno se pregunta: ¿es lícito condenar el excesivo nacionalismo mexicano si uno piensa en naciones como Corea del Sur y Taiwán?

Estos países generaron estructuras productivas propias y superaron la fase maquiladora de décadas pasadas apoyándose en su soberanía nacional. ¿Es previsible que México logre resultados parecidos mediante la aceptación acrítica del ELIFFIT? Desde nuestra perspectiva sería oportuno tener muy en cuenta la opinión de Benito Juárez, mencionada en el comienzo, uno de los constructores de la nación mexicana. Para ser libre y soberano, no conviene que México espere que otras naciones ni las ET hagan por él "lo que México no haga por sí mismo". Hasta ahora, el nuevo regionalismo que está surgiendo en el bloque norteamericano, claramente escindido en centro y periferia, se ha convertido en un instrumento de la hegemonía estadounidense (Mittelman, 2000:140). De ahí que Estados Unidos, más que 
Canadá, emplee dicho naciente regionalismo como instrumento para fortalecer su alicaído predominio en el continente americano.

La estrategia neoliberal, encapsulada en el TLCAN y promotora de la apertura indiscriminada y de la flexibilidad productiva y laboral, se ha convertido en la piedra angular de la política internacional del capitalismo estadounidense para contrarrestar el poderío de las empresas europeas (Gilpin, 2000:239). Pero dada la relación asimétrica existente en el bloque norteamericano, las pérdidas para México superan a las ganancias. Hasta autores nada izquierdistas, como Gilpin, reconocen que el impacto de la economía global y neoliberal en los estados es muy desigual. El caso tlaxcalteca no hace sino confirmar esas tendencias discriminatorias de la globalización imperante.

Una visión simplista de la evolución del sector manufacturero en el estado de Tlaxcala consistiría en destacar que el desarrollo industrial producido en esa provincia no es más que un ejemplo típico de la desigualdad regional en el cual se manifiesta la polarización originada por la expansión del capitalismo global (Amin, 1999:70). Tlaxcala se ha convertido en un estado industrial gracias a la inversión foránea y a la apertura propiciada por el gobierno y las élites empresariales mexicanas. No obstante, la pregunta radical es: ¿Han conquistado Tlaxcala y, por tanto, México mayores cuotas de soberanía mediante sus programas de industrialización?, ¿se ha fortalecido el Estado-nación mexicano mediante este tipo de desarrollo industrial?

La primera respuesta obvia es que el gran beneficiado es el capital transnacional, en concreto, el estadounidense y el europeo. A partir de estrategias industriales, a veces contrapuestas, ambos grupos de naciones han desembocado en el diminuto estado de Tlaxcala. Sobresale, en primer lugar, el primero, cuya presencia es notoria por su concentración en la industria del vestido. ¿Por qué se interesa la industria estadounidense del vestido por invertir en Tlaxcala? Para responder es preciso tener en cuenta las nuevas tendencias del comercio global. La clave es que la creciente regionalización de las industrias textil y del vestido significará que los procesos más especializados - tales como el corte y diseño en la industria del vestido- permanecerán en los países centrales (Estados Unidos, Japón, Alemania, Italia), mientras que las ocupaciones peor pagadas irán a la periferia correspondiente en cada bloque de la economía-mundo (Abernathy et al., 1999:223).

En segundo lugar, el caso de México, Centroamérica y El Caribe requiere de un análisis más específico. Tendencias aparentemente contrarias están en juego. Por una parte, Estados Unidos aplicó desde 1974 hasta 1994 el Acuerdo Multifibras, el cual imponía cuotas en el comercio del vestido «para permitir un crecimiento ordenado de importación de vestidos en los Estados Unidos» (Stern, 1987). Pero, por otra parte, ese país promulgó exenciones parciales para permitir la importación de artículos ensamblados en el extranjero que usaran componentes estadounidenses. Son las reglas de la "sección 807". Es evidente que tales leyes favorecieron el establecimiento de maquiladoras en México y El Caribe. En 
consecuencia, la importancia de la ropa procedente de México creció durante la última década. Desde Tlaxcala se puede afirmar que esa tendencia se ha fortalecido desde que entró en vigor el TLCAN. En la última década se ha multiplicado la presencia de empresas del vestido que exportan, de una u otra manera, al país del norte. Es cierto que las importaciones chinas también han crecido durante la última década en Estados Unidos; sin embargo, México conserva muchas ventajas no sólo por razones geográficas. Aunque la subcontratación internacional se ha complicado en los últimos años, la cercanía de México a Estados Unidos seguirá jugando un papel importante por lo que se refiere a la industria del vestido. La expansión de las maquiladoras estadounidenses del vestido en todo el territorio mexicano, concretamente en Puebla y Tlaxcala, continuará de acuerdo con las tendencias ya expuestas.

En tercer lugar, la creciente presencia de los países europeos en Tlaxcala obedece tanto a razones económicas, como geográficas. En el caso de Alemania, la empresa Volkswagen ha permanecido en Puebla desde 1964. Su ubicación en el límite entre ambos estados permite que pueda maquilar con empresas tanto poblanas, como tlaxcaltecas. Es obvio que el principal mercado para las firmas europeas radicadas en México es Estados Unidos. Por otra parte, la multiplicación y diversificación de las firmas europeas en Tlaxcala son un indicio de la pujanza económica adquirida por la Unión Europea, confirmada por el creciente valor del euro frente al dólar.

En definitiva, por tanto, la apertura neoliberal aplicada en el estado de Tlaxcala ha favorecido ante todo a las empresas extranjeras y, después, a las mexicanas, las cuales actúan como maquiladoras del capital extranjero. En esas condiciones, es difícil pensar que experiencias como la tlaxcalteca sirvan a México como punto de apoyo firme para desarrollar una política más ambiciosa en relación con el objetivo de fortalecer los lazos de integración igualitaria en el bloque norteamericano. Estados Unidos desea una cooperación más estrecha con México, siempre que no se toque el tema de la libre movilidad de los trabajadores (Rubio y Purcell, 2004:150). Las nuevas industrias generadas por el capital extranjero en Tlaxcala han creado un número insuficiente de empleos en cantidad y calidad. El desafío que permanece abierto es lograr el famoso paquete completo, tantas veces propuesto por las autoridades mexicanas. 


\section{Apéndice}

Proteccionismo en Inglaterra y Francia, 1821-1913

(medido por ingresos netos aduanales como porcentaje del valor neto de las importaciones)

\begin{tabular}{crr}
\hline Años & Inglaterra & Francia \\
\hline $1821-1825$ & 53.1 & 20.3 \\
$1826-1830$ & 47.2 & 22.6 \\
$1831-1835$ & 40.5 & 21.5 \\
$1836-1840$ & 30.9 & 18.0 \\
$1841-1845$ & 32.2 & 17.9 \\
$1846-1850$ & 25.3 & 17.2 \\
$1851-1855$ & 19.5 & 13.2 \\
$1856-1860$ & 15.0 & 10.0 \\
$1861-1865$ & 11.5 & 5.9 \\
$1866-1870$ & 8.9 & 3.8 \\
$1871-1875$ & 6.7 & 5.3 \\
$1876-1880$ & 6.1 & 6.6 \\
$1881-1885$ & 5.9 & 7.5 \\
$1886-1890$ & 6.1 & 8.3 \\
$1891-1895$ & 5.5 & 10.6 \\
$1896-1900$ & 5.3 & 10.2 \\
$1901-1905$ & 7.0 & 8.8 \\
$1906-1910$ & 5.9 & 8.0 \\
$1911-1913$ & 5.4 & 8.8 \\
\hline
\end{tabular}

Fuente: Chang Ha-Joon (2002), Kicking Away The Ladder. Development Strategy In Historical Perspective, London, Anthem Press, p. 37.

\section{Bibliografía}

Abernathy, Frederick et al. A Stitch in Time, New York, Oxford Univ. Press, 1999.

Alonso, José A., Mujeres, maquiladoras y microindustria doméstica, México, Fontamara, 1991.

, "Efectos del TLCAN en la microindustria del vestido en Tlaxcala", en Comercio Exterior, vol. 47, núm. 2, febrero, 1997, pp. 103-110.

- Maquila domiciliaria y subcontratación en México en la era de la globalización neoliberal, México, Plaza y Valdés, 2002.

Amin, Samir, El capitalismo en la era de la globalización, México, Paidós, 1999.

Barlow, Maude, www.canadians.org/campaigns/ campaigns-tradepub-ftaa2_s.html

Bhagwati, Jagdish, Protectionism, Cambridge, The MIT Press, 1988.

Bluestone Barry y Bennett Harrison, The desindustrialization of America, New York, Basic Books Publishers, 1982.

Calva Tellez, José Luis, México, más allá del neoliberalismo: opciones dentro del cambio global, México, Plaza \& Janes, 2000.
Carrillo Huerta, Mario M. y Laura E. Carrillo, «El análisis económico y el desarrollo sustentable. Antecedentes y perspectivas en México», en Regiones y Desarrollo Sustentable, año I, núm.1, 2001, pp.25-49.

Carrillo Huerta, Mario M., Desarrollo Regional, Puebla: Universidad de Puebla, 2002.

Chang, Ha-Joon, KIicking away the ladder. Development strategy in Historical Perspective, London, Anthem Press, 2002.

Cox, Robert, "Global Perestroika", en Miliband y L. Panitch (editores), New World order? The Socialist Register, 1992.

Dicken, Peter, Global Shift, London, Paul Chapman Publishing Ltd, 1992.

Fröbel, Folker, "Política económica en la crisis. Algunas observaciones desde la perspectiva de los países industrializados", en Isaac Miniam (editor), Transnacionalización y periferia semiindustrializada I, México, Libros del CIDE, 1983, pp. 101-133.

\section{Desarris rollo}


Giddens, Anthony, Más allá de la izquierda y la derecha: el futuro de las políticas radicales, Cátedra, España, 2000. (Editado originalmente como Beyond Left and Right- The Future of Radical Politics, Stanford, Stanford University Press, 1994.)

Gilpin, Robert, The Challenge of Global Capitalism, Princeton, Princeton University Press, 2000.

Gueck, Martin, Heidel Klaus y Kleinert, Uwe, Unternehmensstrategien Im Strukturbruch der Weltwirtschaft, Heidelberg, 1992.

Lie, John, Han Unbound: The Political Economy of South Korea, Stanford, Stanford University Press, 1998.

Martínez Peinado, Javier y José María Vidal Villa, Economía Mundial, Madrid, McGraw Hill, 1995.

Mittelman, James H., The Globalization Syndrome. Transformation and Resistance. Princeton, Princeton University Press, 2000.

Müller Platenberg, Urs, "Lo que todavía puede esperarse de las transnacionales", en Francisco López Segrera (editor), Los retos de la globalización, tomo II, Caracas, UNESCO, 1998, pp. 671708.

Panitch, Leo, Globalization and the State, México, UNAM, 1994.

Rodríguez, O., La teoría del subdesarrollo de la CEPAL, México, Siglo xxi, 1980.
Rubio, Luis y Susan K. Purcell, Mexico under Fox, Boulder, Colorado, Lynne Rienner Publishers, 2004.

Rubio, Luis, ¿Cómo va a afectar a México el Tratado de Libre Comercio?, México, FCE, 1992.

Sassen, Saskia, Globalization and Its Discontents: Select Essays 1984-1998, Nueva York, New Press, 1998.

SEDECO, Directorio de empresas del estado de Tlaxcala, por rama de actividad, Gobierno del estado de Tlaxcala, Tlaxcala, 2003.

Sklair, Leslie, Assembling for development. The Maquila Industry in Mexico and the United States, Boston, Unwin Hyman, 1988.

Stern, Robert M. (editor), US Trade Policies in a changing World Economy, Cambridge, The MIT Press, 1987.

Unikel, Luis et al., El desarrollo urbano de México. Diagnóstico e implicaciones futuras, México, El Colegio de México, 1976.

Von Bertrab, Hermann, El redescubrimiento de América. Historia del TLC, México, FCE, 1996.

Wallerstein, Immanuel, "The Rise and Future Demise of the World Capitalist System: Concepts for Comparative Analysis", en Comparative Studies in Society and History, núm. 16, 1974.

, "Analysis de los Sistemas Mundiales", en Anthony Giddens et al. (editores), La teoría social hoy, México, Alianza, 1987.

\section{DeSarrrollo}

